Table 2. Characteristics of patients with and without poor outcome

\begin{tabular}{|c|c|c|c|}
\hline & $\begin{array}{l}\text { With Poor Outcome } \\
n=16\end{array}$ & $\begin{array}{l}\text { Without Poor Outcome } \\
n=78\end{array}$ & p value \\
\hline Gender (male, \%) & $9(56.3)$ & $40(51.3)$ & 0.72 \\
\hline Type of neurological involvement, p-NBS & $15(93.8)$ & $37(47.4)$ & 0.001 \\
\hline Age at Behçet diagnosis (year) & $30.7 \pm 11.0$ & $28.9 \pm 9.2$ & 0.50 \\
\hline Age at neurological involvement (year) & $38.9 \pm 12.2$ & $35.5 \pm 11.9$ & 0.307 \\
\hline Initial $m R S \geq 3$ & $14(87.5)$ & $19(24.4)$ & $<0.001$ \\
\hline Genital ulcer & $10(62.5)$ & $61(78.2)$ & 0.21 \\
\hline Skin involvement (PPE+EN) & $12(75)$ & $60(76.9)$ & 1.00 \\
\hline Musculoskeletal involvement & $10(62.5)$ & $36(46.2)$ & 0.23 \\
\hline Ocular involvement & $10(62.5)$ & $37(47.4)$ & 0.27 \\
\hline Vascular involvement (except SVT) & $1(6.3)$ & $28(35.9)$ & 0.019 \\
\hline Gastrointestinal involvement & $1(6.3)$ & $4(5.1)$ & 1.00 \\
\hline HLA B51 positivity $(n=32)$ & $1(50)$ & $13(43.3)$ & 1.00 \\
\hline \multicolumn{4}{|l|}{ Clinical characteristics } \\
\hline Headache & $6(37.5)$ & $67(85.9)$ & $<0.001$ \\
\hline Fever & $0(0)$ & $6(7.7)$ & 0.585 \\
\hline Paresis & $12(75)$ & $14(17.9)$ & $<0.001$ \\
\hline Pyramidal signs & $14(87.5)$ & $20(25.6)$ & $<0.001$ \\
\hline Sensory symptoms & $11(68.8)$ & $23(29.5)$ & 0.003 \\
\hline Cerebellar symptoms & $7(43.8)$ & $12(15.4)$ & 0.017 \\
\hline Cranial nerve involvement & $3(18.8)$ & $10(12.8)$ & 0.69 \\
\hline Convulsion & $1(6.3)$ & $2(2.6)$ & 0.43 \\
\hline Papiledema & $2(12.5)$ & $22(28.2)$ & 0.23 \\
\hline Nausea-vomiting & $3(18.8)$ & $20(25.6)$ & 0.753 \\
\hline \multicolumn{4}{|l|}{ Treatment } \\
\hline Colchicine & $16(100)$ & $73(93.6)$ & 0.584 \\
\hline Anticoagulation & $5(31.3)$ & $26(33.3)$ & 0.87 \\
\hline Azathioprine & $15(93.8)$ & $70(89.7)$ & 1.00 \\
\hline Cyclophosphomide & $9(56.3)$ & $13(16.7)$ & 0.002 \\
\hline Pulse steroid & $13(81.3)$ & $27(34.6)$ & 0.001 \\
\hline Oral steroid & $16(100)$ & $59(75.6)$ & 0.036 \\
\hline Interferone & $1(6.3)$ & $8(10.3)$ & 1.00 \\
\hline Cyclosporine & $2(12.5)$ & $12(15.4)$ & 1.00 \\
\hline Methotrexate & $1(6.3)$ & $1(1.3)$ & 0.313 \\
\hline Acetylsalicylic acid & $5(31.3)$ & $34(43.6)$ & 0.36 \\
\hline Diazomide & $1(6.3)$ & $13(16.7)$ & 0.451 \\
\hline Total follow-up time (month) & 66.84 (IQR: 67.3 ) & 49.4 (IQR: 80.7 ) & 0.36 \\
\hline
\end{tabular}

Vein Thrombosis

sequela and a total of $5(5.3 \%)$ deaths occurred. Characteristics of patients with and without poor outcome are presented in table 2. In multivariable logistic regression analysis, factors associated with poor outcome were initial mRS (OR $24.2(95 \% \mathrm{Cl} 3.16-108.67))$ and age $>=40$ at NBS diagnosis (OR $4.59(95 \% \mathrm{Cl} 1.02-20.69))$, meanwhile, headache at presentation was associated with a lower risk for poor outcome. (OR $0.22(95 \% \mathrm{Cl} 0.05$ $-0.91)$ )

Conclusion: Neurologic involvement is a detrimental manifestation of BS and causes disability, even death. Patients who have an initial disabling presentation in advanced age are more likely to have poor prognosis. Treatment intensification in this subpopulation might be considered.

References: None

Disclosure of Interests: None declared

DOI: 10.1136/annrheumdis-2020-eular.4734

\section{SAT0274 DESCRIPTIVE ANALYSIS OF FLARES DURING THE LONG-TERM FOLLOW-UP OF PATIENTS WITH BEHÇET'S DISEASE INCLUDED IN REGEB COHORT}

M. Rodríguez Carballeira ${ }^{1}$, R. Solans2, R. Ríos Fernández ${ }^{3}$, B. Escalante ${ }^{4}$, B. Maure ${ }^{5}$, A. Fernández ${ }^{6}$, R. Hurtado ${ }^{7}$, R. Boldova ${ }^{4}$, G. Espinosa ${ }^{8} .{ }^{1}$ Hospital universitari Vall d'Hebron, Internal Medicine, Barcelona, Spain; ${ }^{1}$ Hospital universitari Vall d'Hebron, Internal Medicine, Barcelona, Spain; ${ }^{3} \mathrm{Hospital}$ Clinico San Cecilio, Internal Medicine, Granada, Spain; ${ }^{4}$ Hospital Clinico Zaragoza, Internal Medicine, Zaragoza, Spain; ${ }^{5}$ Hospital Universitario Vigo, Internal Medicine, Vigo, Spain; ${ }^{6}$ Hospital Mollet, Internal Medicine, Barcelona, Spain; ${ }^{7}$ Hospital Elx, Elx, Spain; ${ }^{8}$ Hospital Clinic, Internal Medicine, Barcelona, Spain

\section{Background:}

Objectives: To describe the clinical manifestations and treatment of flares during follow-up in patients with Behçet's disease (BD) included in the REGEB cohort over the last decade.

Methods: The Spanish Registry of BD or REGEB (REGistro de la Enfermedad de Behçet as Spanish nomenclature) Project Group was created by the Spanish Internal Medicine Society in 2009 with the aim of compiling a large cohort of Spanish patients with this rare disorder. By July 2012, REGEB has collected $635 \mathrm{BD}$ patients with a multicentre, longitudinal and consecutive design. Diagnosis of BD was performed on the basis of the International Study Group criteria for BD. Since inclusion in the registry, patients have been followed prospectively and new flares have been recorded, defined as those clinical manifestations which have required initiation or modification of immunosuppressive treatment, or prednisone dose at or higher than $10 \mathrm{mg} / \mathrm{d}$ of prednisone during more than 1 month.

Results: A prospective follow-up of 326 patients included in the registry has been analysed. There are 182 women (56\%) and their average age (SD) at the time of diagnosis was 33 (13) years. The majority of them were Caucasian (91\%). The median follow-up time from BD diagnosis was 180 months, and the prospective follow-up period from the inclusion in the reg istry was 80 months. The cumulative clinical manifestations until the initial registration were oral ulcers in $100 \%$ of patients, genital ulcers in $221(68 \%)$, arthritis in 147 (45\%), erythema nodosum in 96 (29\%), fever in $82(25 \%)$, thrombosis in $74(23 \%)$, anterior uveitis in $76(23 \%)$, retinal vasculitis in 46 $(14 \%)$, posterior uveitis in $35(11 \%)$, aseptic meningitis in $32(10 \%)$, and other neurological manifestations in $15(5 \%)$ patients. One hundred and fifty-six (48\%) patients received immunosuppressants and $47(14 \%)$ biological therapy.

During follow up (period from the inclusion in the REGEB to the last visit) 68 (23\%) patients presented at least a severe outbreak. The median time from the BD diagnosis to the first flare were 170 months. The main clinical manifestations were oral-genital ulcers in $43(63 \%)$ patients, uveitis in 31 (45\%), arthritis in $13(19 \%)$, neurological in $16(24 \%)$, vascular in $10(15 \%)$, and gastrointestinal in $3(4 \%)$ patients. Immunosuppressants were used in 37 (54\%) patients and biological therapy in 14 (21\%). Biological therapy was mostly used due to refractory disease, the majority of cases because ocular manifestations. There were no differences in terms of age, sex, race and previous clinical manifestations between patients who suffered from flares and those who did not. Flares were more frequent in patients who have received previous immunosuppressive or biological treatment (35\% vs $13 \%$ and $48 \%$ vs $19 \%$, respectively) ( $p<0.001$ in both cases), probably reflecting a more severe disease.

Conclusion: The long-term follow-up of BD patients from REGEB cohort showed that 10 years after diagnosis, a fifth of them may continue to present severe flares requiring systemic treatment. The use of biological therapy increased over time and their main indication was refractory disease.

Disclosure of Interests: Mónica Rodríguez Carballeira: None declared, Roser Solans: None declared, Raquel Ríos Fernández: None declared Begoña Escalante: None declared, Brenda Maure: None declared, Alejandra Fernández: None declared, Robert Hurtado: None declared, Rafael Boldova: None declared, Gerard Espinosa Speakers bureau: Glaxo-Smith-Kline, Janssen, Boehringer, Rovi

DOI: 10.1136/annrheumdis-2020-eular.4940

\section{SAT0275 MAINTAINED BENEFIT IN HEALTH-RELATED QUALITY OF LIFE OF PATIENTS WITH GIANT CELL ARTERITIS TREATED WITH TOCILIZUMAB PLUS PREDNISONE TAPERING: RESULTS FROM THE OPEN-LABEL, LONG-TERM EXTENSION OF A PHASE 3 RANDOMIZED CONTROLLED TRIAL}

J. H. Stone ${ }^{1}$, J. Han $^{2}$, S. Unizony ${ }^{1}$, M. Aringer ${ }^{3}$, D. Blockmans ${ }^{4}$ E. Brouwer ${ }^{5}$, M. C. Cid $^{6}$, B. Dasgupta ${ }^{7}$, J. Rech ${ }^{8}$, C. Salvarani ${ }^{9}$, R. Spiera ${ }^{10}$, M. Bao ${ }^{2}{ }^{1}$ Massachusetts General Hospital Rheumatology Unit, Harvard Medical School, Boston, United States of America: ${ }^{2}$ Genentech, South San Francisco, United States of America; ${ }^{3}$ University Medical Center and Faculty of Medicine, TU Dresden, Dresden, Germany; ${ }^{4}$ Department of General Internal Medicine, University Hospitals Gasthuisberg, Leuven, Belgium; ${ }^{5}$ Department of Rheumatology and Clinical Immunology, University of Groningen, University Medical Center, Groningen, Netherlands; ${ }^{6}$ Department of Autoimmune Diseases, Hospital Clínic, University of Barcelona, Institut d'Investigacions Biomèdiques August Pi i Sunyer, Barcelona, Spain; ${ }^{7}$ Southend University Hospital, NHS Foundation Trust, Westcliff-on-Sea, United Kingdom; ${ }^{8}$ Friedrich-Alexander-University Erlangen-Nürnberg, Department of Internal Medicine 3-Rheumatology and Immunology, Universitätsklinikum Erlangen, Erlangen, Germany; ${ }^{9}$ Division of Rheumatology, Arcispedale Santa Maria Nuova-IRCCS, Reggio Emilia, Italy; ${ }^{10}$ Hospital for Special Surgery, Cornell, United States of America

Background: In part 1 of the 52-week, double-blind GiACTA trial, patients with giant cell arteritis (GCA) who received weekly tocilizumab (TCZ) plus prednisone tapering reported improvement in the 36-item Short-Form Health Survey (SF-36) Mental Component Summary (MCS) and Physical Component Summary scores and FACIT-Fatigue scores that were statistically significant and clinically meaningful compared with patients who received prednisone alone. ${ }^{1}$ 
Objectives: To analyze whether benefit in SF-36 MCS was maintained in patients originally assigned to TCZ compared with those originally assigned to placebo (PBO) plus a 26- or 52-week prednisone taper among patients who achieved clinical remission at week 52 and maintained treatment-free clinical remission in the 2-year, long-term extension of GiACTA.

Methods: At the end of part 1, patients entered open-label part 2, in which GCA therapy (including initiation/termination of open-label TCZ and/or GCs) was given at the investigator's discretion according to disease status. Change from baseline in SF-36 MCS score was compared for combined original TCZ $(n=33)$ and PBO $(n=17)$ patients who achieved clinical remission at week 52 and maintained treatment-free (no TCZ or GCs) clinical remission in part 2 using a repeated-measures model. The minimal clinically important difference (MCID) for SF-36 MCS is $>2.5 .^{2}$ Results: During treatment, SF-36 MCS scores in all 50 patients who maintained treatment-free clinical remission in part 2 had diverged between the TCZ and PBO groups as early as 36 weeks after baseline, with greater improvements evident in the TCZ group (Figure). The difference in least square means (LSM) change between TCZ and PBO was statistically significant at week $52(p=0.016)$ and maintained at weeks $100(p=0.023)$ and $156(p=0.002)$. The LSM difference $(95 \% \mathrm{Cl})$ between TCZ and PBO at weeks 52, 100, and 156 was 5.6 (1.1-10.2), 6.5 (0.9-12.1), and 7.4 (2.9-11.9), respectively, exceeding the MCID.

Conclusion: Among patients who maintained treatment-free clinical remission during part 2 of GiACTA, those originally assigned to receive TCZ plus a prednisone taper during part 1 maintained statistically significant and clinically meaningful improvements in SF-36 MCS up to week 156 compared with those originally assigned to receive PBO plus a prednisone taper in part 1. This was true even though neither of the patient groups received TCZ or GC treatment after they achieved clinical remission at week 52.

References:

[1] Strand V et al. Arthritis Res Ther 2019;21:64.

[2] Lubeck DP. Pharmacoeconomics 2004;22:27-38.

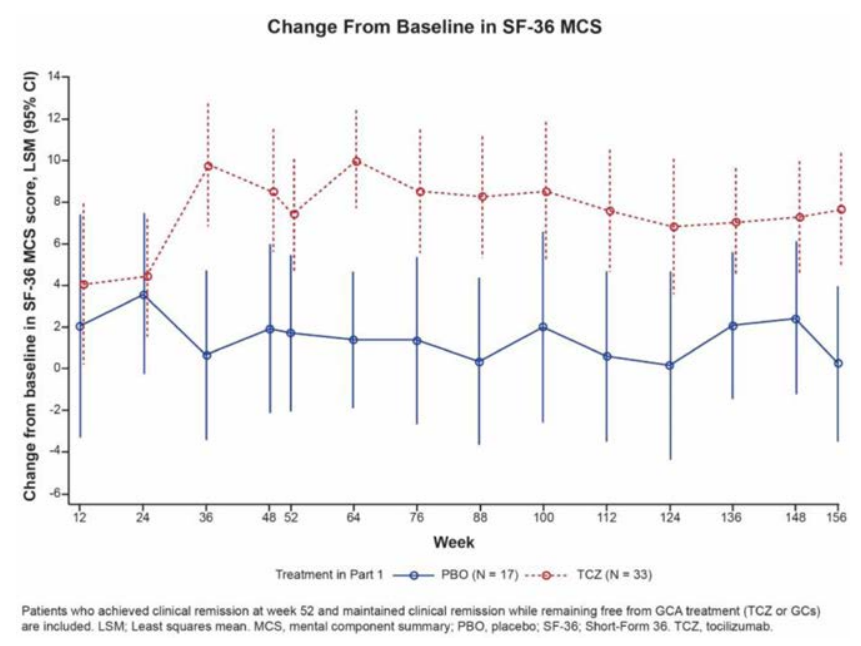

Disclosure of Interests: John H. Stone Grant/research support from: Roche, Consultant of: Roche, Jian Han Shareholder of: Genentech, Inc., Employee of: Genentech, Inc., Sebastian Unizony Grant/research support from: Genentech, Inc., Martin Aringer Consultant of: Boehringer Ingelheim, Roche, Speakers bureau: Boehringer Ingelheim, Roche, Daniel Blockmans Consultant of: yes, Speakers bureau: yes, Elisabeth Brouwer Consultant of: Roche (consultancy fee 2017 and 2018 paid to the UMCG), Speakers bureau: Roche (2017 and 2018 paid to the UMCG), Maria C. Cid Speakers bureau: Roche, Bhaskar Dasgupta Grant/ research support from: Roche, Consultant of: Roche, Sanofi, GSK, BMS, AbbVie, Speakers bureau: Roche, Jürgen Rech Consultant of: BMS, Celgene, Novartis, Roche, Chugai, Speakers bureau: AbbVie, Biogen, BMS, Celgene, MSD, Novartis, Roche, Chugai, Pfizer, Lilly, Carlo Salvarani: None declared, Robert Spiera Grant/research support from: Roche-Genetech, GSK, Boehringer Ingelheim, Chemocentryx, Corbus, Forbius, Sanofi, Inflarx, Consultant of: Roche-Genetech, GSK, CSL Behring, Sanofi, Janssen, Chemocentryx, Forbius, Mistubishi Tanabe, Min Bao Shareholder of: Roche, Employee of: Genentech DOI: 10.1136/annrheumdis-2020-eular.1541

\section{SAT0276 CARDIAC MAGNETIC RESONANCE IMAGING IN PATIENTS WITH BEHCET'S DISEASE: A PILOT STUDY}

A. A. Ahmed ${ }^{1}$, S. Tharwat ${ }^{1}$, N. M. Batouty ${ }^{2}$, S. D. Abd El-Halim ${ }^{1}$ on behalf of No. ${ }^{1}$ Faculty of Medicine, Mansoura University, Rheumatology and Immunology
Unit, Internal Medicine Department, Mansoura, Egypt; ${ }^{2}$ Faculty of Medicine, Mansoura University, Radiology Diagnosis, Mansoura, Egypt

Background: Behçet's disease is a multisystemic vasculitis characterized by mucocutaneous, ocular, arthritic, and vascular manifestations.[1] However, the incidence and nature of cardiac involvement in Behcet's disease have not been clearly documented yet.

Objectives: This study aimed to assess the cardiac involvement in patients with Behçet's disease using cardiac magnetic resonance imaging (MRI).

Methods: This cross -sectional descriptive study was carried out on thirty consecutive patients with Behçet's disease (21 males, 9 females) with mean age $32.3 \pm 8.9$ years and with no evidence of cardiac disease. They underwent cardiac MRI to determine morphological and functional changes of the heart and to detect areas of hyperenhancement after IV administration of gadolinium.

Results: At least one abnormality on cardiac MRI was observed in 20/30 patients (66.67\%). Myocardial oedema was observed in 3 patients $(10.0 \%)$ and late gadolinium enhancement in only 1 patient (3.3\%). Pericardial effusion was found in 3 patients (10.0\%), global hypokinesia in 6 patients $(20.0 \%)$ and intra-cardiac thrombosis in only 1 patient $(3.3 \%)$. Pulmonary artery was dilated in 4 patients (13.3\%). Left ventricular and right ventricular end diastolic volume were altered in 4 patients $(13.3 \%)$ and 7 patients $(23.3 \%)$ respectively. Also, left ventricular and right ventricular end systolic volume were abnormal in7 patients $(23.3 \%)$ and 5 patients $(16.7 \%)$ respectively. Moreover, there was aortic valve regurge in 2 patients $(6.7 \%)$, tricuspid valve regurge in 9 patients $(30 \%)$, and mitral valve regurge in 9 patients (30\%).Dilated left main coronary artery in 2 patients $(6.7 \%)$ and arythmogenic right ventricular dysplasia in only one patient 1 patient (3.3\%). Conclusion: Behçet's disease may cause cardiac abnormalities without clinical manifestations and cardiac MRI may represent a tool for early detection of these subtle abnormalities.

References:

[1] Geri, G., et al., Spectrum of cardiac lesions in Behçet disease: a series of 52 patients and review of the literature. Medicine, 2012. 91(1): p. 25-34.

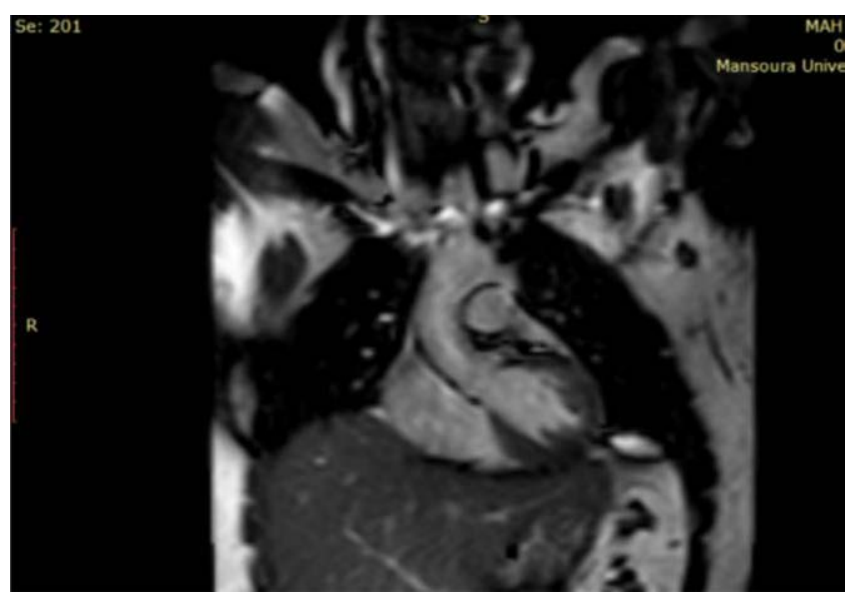

Figure 1. Cardiac MRI in 32 year-old female patient with Behçet's disease for 3 years.

Acknowledgments: : The authors would like to acknowledge Ahmed El Bahy for his assistance with this study

Disclosure of Interests: None declared

DOI: 10.1136/annrheumdis-2020-eular.5232

\section{SAT0277 HEAD AND NECK INVOLVEMENT OF IGA VASCULITIS: A CASE-CONTROL STUDY}

M. Villatoro Villar ${ }^{1}$, D. A. Wetter ${ }^{2}$, C. S. Crowson ${ }^{3}$, K. J. Warrington ${ }^{3}$, M. Koster ${ }^{3}$. ${ }^{1}$ The University of Arizona, Rheumatology, Tucson, AZ, United States of America; ${ }^{2}$ Mayo Clinic, Dermatology, Rochester, MN, United States of America; ${ }^{3}$ Mayo Clinic, Rheumatology, Rochester, MN, United States of America

Background: IgA vasculitis (IgAV) is an immune-complex mediated, small-vessel vasculitis which predominantly involves the skin on the lower extremities. Head and neck involvement is rarely reported.

Objectives: To describe the presentation and outcome of a series of patients with head and/or neck involvement in comparison to patients with cutaneous findings isolated to the lower extremities. 